\title{
DEMOCRACIA, CIDADANIA E DIREITO FUNDAMENTAL À EDUCAÇÃO: ELEMENTOS DE EFETIVAÇÃO E VINCULATIVIDADE
}

\author{
Rogério Luiz Nery da Silva ${ }^{1}$ \\ Darléa Carine Palma Mattiello ${ }^{2}$
}

RESUMO: A pesquisa possui como tema a democracia e suas relações com efetiva prestação educacional, considerando que democracia, cidadania e educação são interdependentes. $\mathrm{O}$ problema de pesquisa consiste em esclarecer qual o nível de entrelaçamento entre democracia, cidadania e educação na América Latina. Objetiva-se vincular os conceitos determinantes de democracia em Guillermo O'Donnell com a educação enquanto meio de empoderamento, com base na experiência latino-americana. Utiliza-se pesquisa bibliográfica e documental, com abordagem qualitativa e método hipotético-dedutivo. Em conclusão, elucida-se o quão determinante é a efetividade do direito à educação para fortalecimento dos processos democráticos e a edificação da cidadania.

PALAVRAS-CHAVE: Democracia; cidadania; direitos fundamentais sociais; educação; América Latina.

\section{DEMOCRACY, CITIZENSHIP AND THE FUNDAMENTAL RIGHT TO EDUCATION: ELEMENTS OF EFFECTIVENESS AND BINDING}

\begin{abstract}
The research has as its theme democracy and its relationships with effective educational provision, considering that democracy, citizenship and education are interdependent. The research problem is to clarify the level of intertwining between democracy, citizenship and education in Latin America. The objective is to link the determinant concepts of democracy in Guillermo O'Donnell with education as a means of empowerment, based on the Latin American experience. Bibliographic and documentary research is used, with a qualitative approach and hypothetical-deductive method. In conclusion, it elucidates how decisive the effectiveness of the right to education is for strengthening democratic processes and building citizenship.
\end{abstract}

KEYWORDS: Democracy; citizenship; social fundamental rights; right to education; Latin America.

\section{INTRODUÇÃO}

\footnotetext{
${ }^{1}$ Pós-Doutor pela Université de Paris X (França) e pela New York Fordham University (USA). Doutor em Direito pela Unesa. Posgrado en Justicia y Procesos Constitucionales pela Universidad Castilla-La Mancha (Espanha). Professor Programa Erasmus (União Europeia) na Cardinal Stefan Wyszynski University (Varsóvia Polônia). Professor na Università degli Studi di Foggia (Itália). Professor-Doutor no Mestrado e Doutorado em Direito da Unoesc. Advogado. Endereço postal: Av. Nereu Ramos, 3777-D, Seminário, Chapecó/SC, CEP 89813-000. Endereço eletrônico: dr.nerydasilva@ gmail.com. ORCID: https://orcid.org/0000-0003-4317-5903. Lattes: http://lattes.cnpq.br/127540036993255.

2 Doutoranda em Direito pela Universidade do Oeste de Santa Catarina (Unoesc). Mestre em Direito pela Unoesc, com período sanduíche na Università degli Studi di Foggia (Itália). Pesquisadora vinculada ao Programa de Pós-Graduação em Direito da Unoesc. Professora na graduação e pós-graduação da Unoesc. Editora assistente da Revista Espaço Jurídico Journal of Law (CAPES Qualis A1). Advogada. Endereço postal: Av. Nereu Ramos, 3777-D, Seminário, Chapecó/SC, CEP 89813-000. Endereço eletrônico: darlea.palma@unoesc.edu.br. ORCID: http://orcid.org/0000-0003-1342-4681. Lattes: http://lattes.cnpq.br/4357591928586392.
} 
Ao se pensar em democracia, inafastável é a necessidade do estabelecimento de conceitos que, além de vincular o tema às ideias basilares de Estado e de participação popular, apresentem pilares aptos a vincular o regime democrático com o exercício dos direitos fundamentais. Quando se abordam os direitos sociais, especialmente, tecer noções conceituais apresenta singular relevância, porquanto são fixados limites de análise e de contexto para apreciação adequada do quão democrático - e cidadão - pode revelar-se determinado Estado. Até porque a democracia realiza-se no Estado, de forma pautada, muitas vezes, no quão efetiva é a prestação educacional aos seus cidadãos.

Nesse panorama, apresenta-se como problema de pesquisa a necessidade de esclarecer qual a inter-relação existente entre a democracia, a cidadania e o direito à educação, no contexto dos direitos sociais a serem prestados pelo Estado. Objetiva-se, a partir daí, apresentar as teorias sobre a democracia lançadas por Guillermo O’Donnell e os principais conceitos do direito à educação, a fim de traçar a relação da efetividade da educação com a consolidação da democracia na América Latina.

Além das considerações teóricas, o presente estudo analisa dados do índice de desenvolvimento humano (IDH) e de efetividade educacional divulgados pelo Programa das Nações Unidas para o Desenvolvimento (PNUD) referentes aos países classificados nos estudos sobre democracia por O’Donnell como aqueles nos quais o regime e o estado característicos da democracia estão basicamente satisfeitos, comparando-os com outros países da América Latina sem a mesma consolidação democrática.

A fim de elucidar o problema proposto, adota-se a pesquisa bibliográfica e documental, de caráter qualitativo, com predominância do método hipotético-dedutivo, a partir de revisão da literatura aplicável à espécie, partindo-se da hipótese que, para aferir a consolidação da democracia em determinado contexto geográfico e histórico, revela-se proeminente vincular suas teorias com a efetividade do direito à educação.

Com o mesmo intuito elucidativo, divide-se, estruturalmente, o desenvolvimento do trabalho em três partes distintas: a primeira, voltada a apresentar premissas teóricas sobre democracia, Estado e cidadania; a segunda, destinada a tecer conceitos sobre a educação enquanto direito social vinculado ao desenvolvimento dos povos; e a terceira, disposta a analisar os dados de IDH e de efetividade educacional divulgados pelo PNUD, para esclarecer os elos existentes entre o fortalecimento democrático, os direitos fundamentais sociais e, principalmente, o direito à educação. 


\section{DEMOCRACIA, ESTADO E CIDADANIA NO SEIO DO DEBATE CONCEITUAL}

Pode-se afirmar que cidadania, o funcionamento do Estado e o exercício de direitos são pilares interpretativos essenciais para compreender a democracia. Estabelece-se uma relação de interdependência entre os três elementos quando analisados histórica e geograficamente, a ponto de se perceber que a democracia é mais ou menos desenvolvida conforme se tem a efetividade de direitos aos cidadãos em determinados Estados.

Ao abordar os conceitos formais de democracia, Ferrajoli (2012) defende que, conforme as concepções atuais, democracia é a forma de governo na qual poder é exercido por todas as pessoas, por sua maioria, seja diretamente ou por meio de representantes. Segundo o autor, não se trata, esse, apenas, de um significado etimológico, mas também uma noção que se repete ao longo da história do pensamento político. ${ }^{3}$

Essa dimensão formal da democracia relacionada à vontade popular como legitimadora do poder, entretanto, segundo Ferrajoli (2012, p. 69), embora se constitua em condição sine qua non para se falar em "democracia", não é única condição necessária, nem suficiente, para estabelecer o espaço democrático. Defende o autor que essa dimensão seja integrada por limites ou restrições substanciais ou de conteúdo, relacionados aos direitos constitucionais fundamentais.

Nesse sentido, significativo é o estudo de O’Donnell (2004) sobre a democracia na América Latina, pautado nas definições de Estado, regime democrático e cidadania, de forma conexa com as ideias de efetividade da ordem jurídica e direitos fundamentais, dentre outros temas conexos. Daí a relevância de sua análise para compreender a vinculação entre democracia, cidadania e os direitos sociais - especialmente o direito à educação - no contexto brasileiro.

As ideias de O’Donnell (2004, p. 11) assentam-se, inicialmente, na premissa de que o regime democrático é insuficiente para caracterizar adequadamente a democracia. De qualquer forma, entende o autor que o regime é componente indispensável da democracia, assim como também são importantes para tal caracterização o estado e o contexto social geral em que se insere a análise.

\footnotetext{
${ }^{3}$ Segundo o autor (FERRAJOLI, (2012, p. 69), “[...] dalla classica tripartizione introdotta da Platone nel Politico e represa da Aristotele all'idea rousseauviana della volontà generale come autodeterminazione di tutti e di ciascuno, fino alle odierne teorie della democrazia rappresentativa, da Kelsen a Bobbio, da Schumpeter a Dahl, da Popper a Waldron."
} 
Outro pilar apresentado por O’Donnell (2004, p. 11) é o fato de que a especificidade histórica merece especial atenção para o estudo da democracia em todo o mundo, inclusive na América Latina. Em paralelo, uma terceira base proposta para a discussão é que a democracia se baseia em uma concepção do ser humano como agente, que pode ser detectada conforme o nível do regime e indagada em outras dimensões, conforme necessitam as implicações de análise (O’DONNELL, 2004, p. 11).

A análise de O’Donnell foi apreciada por outros estudiosos do tema, os quais, ao assentar suas ideias sobre democracia com base nas premissas e conclusões esboçadas pelo autor supracitado, explicitam elementos determinantes para análise da efetividade dos direitos sociais no contexto geográfico ora em estudo.

Ao discutir a nacionalização e democratização do Estado, a política e a sociedade, Cotler (2004, p. 123) tece considerações sobre a fala de O'Donnell acerca da democracia do noroeste $^{4}$ e de como essa democracia poderia ser referência política para as sociedades e governos da América Latina, apesar das diferenças notáveis em suas condições sociais e trajetórias históricas. Enquanto o autor assume a democracia como produto de construção social, faz uma análise sugestiva de fatores contribuintes para que o noroeste tivesse atingido níveis democráticos mais elevados (O’DONNELL, 2004, p. 123).

Held (2004, p. 127), por sua vez, ao tratar do estado da democracia na América Latina, entende que se deve explorar o papel da cultura na democracia, sustentando-se que o desenvolvimento de uma cultura tolerante, com diversidade de opiniões e desafios democráticos competitivos são elementos cruciais que devem ser aprendidos para apoiar uma política democrática (HELD, 2004, p. 128).

A vinculação entre a qualidade da democracia conforme a influência da sociedade civil é considerada por Méndez (2004, p. 131), partindo da premissa que os sistemas políticos democráticos da América Latina, e especialmente seus líderes, têm, em geral, hostilidade a organizações independentes da sociedade civil, o que pode ser uma causa para a baixa qualidade da democracia - a denominada cidadania de baixa intensidade. Nesse contexto, sustenta o autor que, por meio das organizações independentes da sociedade civil, os cidadãos participam mais cotidianamente da formulação, implementação e avaliação das políticas

\footnotetext{
${ }^{4}$ O’Donnell (2004), em suas considerações, toma como base o que aconteceu no espaço territorial que denomina de noroeste, referindo-se aos países norte-americanos, para propor que a América Latina, mediante a correção de erros, também atinja altos padrões.
} 
públicas e do controle dos atos do governo. Ao fazê-lo em defesa de interesses que não são seus, eles alcançam uma cidadania mais plena (MÉNDEZ, 2004, p. 132).

Já a análise de Rosanvallon (2004, p. 193) sobre o tema cuida das dimensões social e nacional da democracia, rumo a um marco de compreensão ampliada, estendida, defendendo a necessidade de captar a dimensão corporativa, societária, do fato democrático, relacionando "democracia política" com "democracia social”. Sustenta que a democracia também se caracteriza como uma forma de sociedade, e não, apenas, como uma situação de inclusão em uma comunidade de cidadãos. Assim, não se poderia adotar a concepção do direito de votar e da garantia de contar com a proteção de certo número de liberdades individuais para definir totalmente o que é democracia (ROSANVALLON, 2004, p. 194-195).

Rosanvallon (2004, p. 195-196), dessa forma, refere-se à "democracia vista de baixo", afirmando que pode ser útil analisa-la a partir das desilusões experimentadas pelos cidadãos, pois a democracia não pode ser apenas um "modelo" a ser implementado, pois é vivida como uma história, uma experiência. Assim, ao falar sobre a democracia e suas patologias, sustenta que a exploração dos "abismos" da democracia é uma via privilegiada para compreendê-la.

Tem-se, assim, uma proximidade entre democracia, cidadania e o exercício de direitos, considerando-se que o regime adotado pelo estado dita, via de regra, com maior ou menor efetividade, a realização das previsões normativas consolidadas. Tratam-se, assim, de temas não segmentados, mas, sim, complementares e vinculados.

Não à toa, O’Donnell (2004) apresenta as seguintes três dimensões da cidadania: política, civil e social. No mesmo sentido, Marshall (1997, p. 304) considera uma visão tripartida de cidadania, compreendida mediante o desenvolvimento dos direitos civis, políticos e sociais, com formação e desenvolvimento em momentos históricos diversos, estabelecidos - ainda que de forma flexível - como os direitos civis no século XVIII, os políticos no século XIX e os sociais no século XX.

Marshall (1997, p. 304) sustenta que a evolução da cidadania pressupõe um duplo processo, compreendendo fusão e separação. Nesse sentido, a fusão seria geográfica e a separação, funcional. Esclarece, assim, que os três elementos da cidadania separaram-se em determinado momento, após se desenvolverem, o que pode ser determinante para o estabelecimento maior ou menor da democracia. 
O resumo do processo de democratização no noroeste, de que a agência ${ }^{5}$ é a chave, segundo Cotler (2004, p. 125), permite a O'Donnell destacar que sua ausência na América Latina, com exceção de alguns países (Costa Rica, Chile e Uruguai, por exemplo), constitui o segredo de sua trajetória única e a dificuldade que tem para consolidar o regime e o estado democráticos.

Seria assim porque a ação coletiva privilegiou a reivindicação dos direitos políticos e sociais, a despeito dos direitos civis, cujo cumprimento e incorporação na consciência social constituem condição necessária para garantir a autonomia e capacidade individual de assumir com responsabilidade a escolha entre opções alternativas e suas consequências.

Ao se falar em direitos políticos, explícita se torna a vinculação com a questão democrática, porquanto o voto é a grande e popular manifestação da democracia. O mesmo ocorre com relação aos direitos civis, que, por natureza, conferem liberdade ao cidadão. Quanto aos direitos sociais, entretanto, é necessário estabelecer a relação que se forma entre esses e a democracia, a fim de esclarecer o elo entre o regime democrático, a cidadania e a educação, que é um direito prestacional por natureza.

\section{DIREITOS SOCIAIS, DESENVOLVIMENTO E EDUCAÇÃO}

Uma educação de qualidade, formadora do ser humano cidadão, perpassa pela possibilidade de participação ativa e livre na vida democrática. Nesse sentido, no Brasil, destacam-se as palavras proferidas por Paulo Freire (1989, p. 80), para quem a educação "tradicional" frutificou em virtude de a sociedade não conseguir fomentar a sua própria democracia. Chega-se, a partir dessas afirmações, à concepção de democracia como sendo aquela que é realizada pelo próprio povo. ${ }^{6}$

Reforça-se, dessa forma, a ideia freiriana de que a democracia, antes de ser um método político, é um estado humano de construção histórico-social, que se orienta conforme a humanização, por meio da educação e da política (FREIRE, 1989). Como via de

\footnotetext{
${ }^{5}$ Cotler (2004) segue as concepções de O'Donnell sobre o termo "agência", tecidas a partir da análise de J. Waldron (in Law and Disagreement, Oxford, Clarendon Press, 1999, p. 222): "Éste es un aspecto extremadamente importante, aunque olvidado, de la democracia: la presunción de agencia implicada por el régimen democrático constituye a cada individuo como una persona legal, portadora de derechos subjetivos. La persona legal elige opciones, y se le asigna responsabilidade por ello, porque el sistema legal presupone que es autónoma, responsable y razonable - repito, es un agente."

${ }^{6}$ Nos dizeres de Freire (1989, p. 80), tal democracia “[...] é forma de vida e se caracteriza, sobretudo, por forte dose de transitividade de consciência no comportamento do homem. Transitividade que não nasce e nem se desenvolve a não ser de certas condições em que o homem seja lançado ao debate, ao exame de seus problemas e dos problemas comuns. Em que o homem participe".
} 
consequência, tem-se que o desenvolvimento da cidadania é corolário vinculado para o empoderamento conferido pela educação. Isso porquanto a educação e a política - unidas forjam uma consciência crítica, desenvolvendo e fortalecendo os processos democráticos.

Por outro lado, a inefetividade na prestação do direito à educação desfavorece o ambiente democrático, ou seja, quanto mais for efetiva a prestação educacional, e com qualidade, mais profícuo será o ambiente para a democracia. Nesse sentido, segundo Santos, "o desenho de novas formas de emancipação social tem seu traçado construído a partir de práticas que ocorrem em contextos específicos, para dar respostas a problemas concretos" (2002, p. 71).

Segundo Marshall (1997, p. 310), o exercício do direito à educação possui ligação direta com a cidadania e, por consequência, com a democracia. Nesse sentido, assevera que o direito à educação é um genuíno direito social de cidadania e complementa afirmando que a educação das crianças implica de forma imediata na cidadania, estimulando, em potencial, o crescimento dos cidadãos. ${ }^{7}$ Considera-se, assim, o alcance do direito à educação para o exercício da cidadania, da mesma forma como se estabelece a intrínseca relação entre os direitos sociais e civis nesse ponto. ${ }^{8}$

Ao afirmar que: "Estamos ante un derecho personal combinado con una obligación pública de ejercer el derecho", Marshall (1997, p. 311) explicita que a educação deve ser prestada pelo Estado para que possa ser efetivamente exercida pelos cidadãos. Por via de consequência, nasce a obrigatoriedade da implementação de políticas públicas adequadas não apenas para inserção, mas, também, para permanência dos alunos nas instituições de ensino, a fim de lhe conferir, efetivamente, o ensino como forma de autonomia, surgindo, por consequência, a inegável vinculação entre cidadania, educação e o exercício da democracia. ${ }^{9}$

\footnotetext{
${ }^{7}$ Nos termos do autor “[...] La educación de los niños tiene implicaciones inmediatas para la cidadanía, y cuando el Estado garantiza que todos los niños recibirán educación, tiene en mente todos los requisitos y la naturaleza de la cidadanía. Trata de estimular el crecimiento de ciudadanos en potencia. El derecho a la educación es un genuino derecho social de ciudadanía, porque el objetivo último de la educación en la infancia es crear al futuro adulto" (MARSHALL, 1997, p. 310).

${ }^{8}$ Em esclarecimento, leciona Marshall (1997, p. 311): "debe considerarse esencialmente no el derecho del niño de ir a la escuela, sino el derecho del ciudadano adulto a recibir educación. Y aquí no hay conflicto alguno con los derechos civiles tal y como se interpretaban en la era individualista. Porque los derechos civiles estaban diseñados para que hicieran uso de ellos personas razonables e inteligentes, que habían aprendido a leer y escribir. La educación es un prerrequisito necesario para la liberdad civil".

${ }^{9}$ Sendo, portanto, inegável a vinculação entre cidadania e a educação, Marshall (1997, p. 311) conclui por sua ligação com o exercício da democracia, afirmando que "[...] A medida que se entraba en siglo XX, se tomó cada vez más conciencia de que la democracia política precisaba un electorado educado, y que la manufactura científica precisaba trabajadores y técnicos cualificados. [...] De lo que sigue que la extensión de la educación
} 
Tem-se, dessa forma, o direito à educação como um direito social por excelência, sem que se desvincule o seu exercício como determinante para a efetivação dos direitos civis. Invoca-se, aqui, a consagrada concepção de Alexy (2015, p. 433-434), para quem os direitos à assistência social, ao trabalho, à moradia e à educação constituem o que é denominado “direito a prestações", ou seja, os direitos a uma ação positiva do Estado, que pertencem a um status positivo, em sentido estrito.

Em contraponto, viriam os direitos de defesa do cidadão contra o Estado, constituindo-se direitos a ações negativas do Estado. Na esteira dessa classificação, têm-se as palavras de Sarlet (2012, p. 260), ao afirmar que os direitos fundamentais, em razão de sua multifuncionalidade, podem ser classificados basicamente em dois grandes grupos, nomeadamente os direitos de defesa e os direitos a prestações. Incluem-se, segundo o autor, no primeiro grupo os direitos de liberdade, igualdade, as garantias, bem como parte dos direitos sociais (no caso, as liberdades sociais) e políticos; o segundo grupo, por sua vez, integra-se pelos direitos a prestações, representados pelos direitos sociais de natureza prestacional, dentre os quais figura o direito à educação (SARLET, 2012, p. 260).

Essa liberdade que se expande ao âmbito privado não permite esquecer o ensino, como resultante desses múltiplos vetores; é um dos componentes da educação e concorre à satisfação de um direito essencial dos seres humanos, de cuja realização depende a efetividade de vários outros direitos (WACHSMANN, 2013).

$\mathrm{O}$ direito à educação constitui-se em um dos pilares do Estado Democrático de Direito, uma vez que pode (e deve) ser prestado e exigido, de forma permanente e indistinta a todos os cidadãos, para corresponder aos anseios do povo destinatário da atuação estatal. Até porque a democracia não se faz só: exige-se uma conjuntura de valores comuns, revelados por instituições, práticas e hábitos que reflitam os princípios democráticos e os reforcem. E sendo a fundamentalidade inerente ao direito à educação, resta ela, por consequência, dependente de prestações estatais positivas, assim como os demais direitos sociais.

A educação é um dos direitos humanos, tendo sido reconhecida como tal no art. 26 da Declaração Universal dos Direitos Humanos de 1948. O direito humano à educação reconhecido na Declaração foi fortalecido como norma jurídica internacional, principalmente, pelo Pacto Internacional dos Direitos Econômicos, Sociais e Culturais (arts. 13 e 14), da

básica pública durante en siglo XIX fue el primer paso decisivo en la senda del restablecimiento de los derechos sociales de cidadanía en el siglo XX". 
Convenção Relativa à Luta contra a Discriminação no Campo do Ensino, da Convenção sobre os Direitos da Criança (arts. 28 e 29) e do Protocolo Adicional à Convenção Americana sobre Direitos Humanos em Matéria de Direitos Humanos Econômicos, Sociais e Culturais (art. 13) (ONU, 1948).

Assim, tratar a educação como um direito humano repercute ao presente estudo, pois significa que não deve depender das condições econômicas dos estudantes ou estar sujeita unicamente às regras de mercado. Também não pode estar limitada à condição social, nacional, cultural, de gênero ou étnico-racial da pessoa. O mais importante é conseguir que todas as pessoas possam exercer e estar conscientes de seus direitos. Nesse sentido, o tópico 2 do art. 26 da Declaração foi fundamental na definição dos propósitos universais da educação.

Também nesse sentido são as palavras de Keohane (2015), para quem, em democracias bem estabelecidas, tais práticas são reforçadas nacionalmente, fazendo com que a democracia funcione e seja objeto de adesão, por meio de uma infraestrutura legal, institucional e da sociedade civil. ${ }^{10}$

Não poderia ser diferente, evidenciando-se, também nesse ponto, a vinculação entre a democracia e o desenvolvimento da educação enquanto direito social. Afinal, a educação é fundamental para o desenvolvimento das pessoas, seja qual for o arcabouço legislativo em que se encontre prevista e/ou o conteúdo jurídico ao qual se vincula o seu exercício. Ao ser discriminada como direito fundamental ${ }^{11}$, não pode ter sua prestação mitigada, sob pena de ofender, até mesmo, a própria dignidade das pessoas humanas destinatárias do texto constitucional. $^{12}$

De modo geral, os sujeitos destinatários dos direitos sociais exigem tratamento individualizante e local, comprometendo o tema com o multiculturalismo e com a adequação das realidades específicas da realidade a ser tutelada. Por consequência, deve-se reconhecer que os direitos fundamentais são prerrogativas do indivíduo em face do Estado, o que culmina por abranger, nessa condição, os direitos individuais, políticos e sociais. A fundamentalidade

\footnotetext{
${ }^{10} \mathrm{O}$ autor (Keohane, 2015) afirma: "Democracy requires a substantial measure of common values, institutions that reflect its principles, and a well-established set of practices, or habits, that reinforce it. These practices are reinforced, in well-established democracies, by traditions and symbols with emotional value. Without the legal, institutional, and civil society infrastructure that makes democracy work, nominal adherence to democratic principles at a global level will be illusory."

${ }^{11}$ Acerca das discussões sobre a fundamentalidade do direito à educação, destaca-se a posição de Black (2019), para quem, efetivamente, o direito à educação vem enfrentando barreiras.

${ }^{12}$ Fortalecendo esse argumento, afirma Maliska (2001, p. 57): "Se o mundo, hoje, fala em democracia como sendo o regime mais adequado à sociedade moderna, deve, necessariamente, ter também presente que, sem um Estado que propicie condições para a emancipação de seus cidadãos, não se pode nem pensar em democracia".
} 
explicitada no texto constitucional e em convenções internacionais, nesse contexto, também se relaciona com o aspecto de os direitos sociais vincularem-se à dignidade.

Dessa forma, percebe-se que é intensa a discussão sobre os direitos fundamentais sociais serem considerados unicamente prestacionais. É indiscutível, porém, o papel dos direitos sociais na busca do bem-estar coletivo, independentemente das mutações verificadas na evolução do Estado de Direito e ainda que transite entre uma perspectiva abstencionista ou prestacional. Portanto, verifica-se que de tal discussão não pode se afastar o direito à educação, que é fundamental e prestacional por natureza.

Fator importante nesse contexto é que a educação deve ser assegurada não apenas sob a forma de acesso e permanência nas instituições escolares, mas, sim, como instrumento para fornecer às pessoas conhecimento e opções de escolha, tornando-as aptas a inserção, permanência e respeito no convívio social.

Sobre o direito à educação configurar-se em um direito subjetivo, invocam-se as palavras de Garcia (2004), para quem tanto o direito objetivo como o subjetivo possuem um epicentro comum: a pessoa, natural ou jurídica, que é a titular em potencial das relações jurídicas que se desenvolvem no organismo social. Nessa linha de pensamento, enquanto o direito objetivo ocupa uma vertente externa à pessoa, mas a ela direcionada, o direito subjetivo se realiza na própria pessoa, razão de situar o direito à educação como direito subjetivo.

\section{DIREITO À EDUCAÇÃO: ELOS COM O FORTALECIMENTO DEMOCRÁTICO}

Os elementos de fundamentalidade e subjetividade do direito à educação são determinantes para o pleno fortalecimento dos cidadãos. O pleno exercício do direito à educação é elemento centralizador para o exercício de vários outros direitos inerentes à dignidade da pessoa humana, inclusive para que se possa exercer, autonomamente, a democracia.

Maliska (2001, p. 161) sustenta que, quando a sociedade é composta por cidadãos ativos, exercendo plenamente a sua cidadania, tem-se o exercício do legítimo poder democrático, devendo-se compreender a cidadania não em um sentido formal e abstrato, mas 
quando se verifica uma participação ativa dos envolvidos. E isso inclui uma grande gama de destinatários da ação estatal. ${ }^{13}$

O direito à educação e o princípio a dignidade da pessoa humana tanto se relacionam que várias declarações de direitos ressaltam a relevância da educação para uma vida digna, assim como a inserem no rol dos direitos fundamentais. No sentido de esclarecer que a dignidade da pessoa humana é ponto central ("núcleo duro") dos direitos fundamentais para vários povos, consoante explicitado nas várias declarações de direitos, esclarecem Baez e Mozetic (2013) que devem ser examinados os valores propostos com uma visão intercultural, sem o condão de atribuir supremacia de uma nação sobre a(s) outra(s), haja vista a existência de culturas antagônicas que impossibilitaram, até a atualidade, o entendimento global sobre uma categoria universal de direitos fundamentais.

$\mathrm{Na}$ esteira do que preconiza Wachsmann (2013, p. 721), equivale a afirmar que esse direito fundamental propicia as condições de realização e eficácia de outros direitos e liberdades, ou seja, sem o direito à educação, qual não pode haver sociedade livre ${ }^{14}$. A educação, assim, embora considerada um direito social, é imprescindível à salvaguarda de um direito que, sob um prisma lógico-evolutivo, o antecede na formação do Estado de Direito: a liberdade (GARCIA, 2004), demonstrando que direitos de primeira e de segunda dimensões, sejam definidos como negativos ou positivos, de defesa ou prestacionais, podem - e devem conviver de forma afinada, indissociável e com nexo de complementaridade.

Independentemente da limitação geográfica e temporal em que se insira, o nível de exercício da cidadania pelo povo sempre será determinante para o fortalecimento do processo democrático interno em uma nação. Em concordância, afirmam Santos e Avritzer (2002, p. 42) que: "O processo de globalização suscita uma nova ênfase na democracia local e nas variações da forma democrática no Estado nacional”.

\footnotetext{
${ }^{13}$ Nas palavras de Gadotti (2009, p. 22): "O direito à educação não se limita às crianças e jovens. A partir desse conceito, devemos falar também de um direito associado - o direito à educação permanente -, em condições de equidade e igualdade para todos e todas. Como tal, deve ser intercultural, garantindo a integralidade e a intersetorialidade. Esse direito deve ser garantido pelo Estado, estabelecendo prioridade à atenção dos grupos sociais mais vulneráveis. Para o exercício desse direito, o Estado precisa aproveitar o potencial da sociedade civil na formulação de políticas públicas de educação e promover o desenvolvimento de sistemas solidários de educação, centrados na cooperação e na inclusão."

14 "Mais il ne faut perdre de vue que l'ensemble formé par l'enseignementprivé concourt à la satifaction d'un droit essentiel, dont la réalisation conditionne l'effectivité des autres droits et libertés: le droit à l'instruction, sans lequel il ne peut y avoir de societé libre" (WACHSMANN, 2013, p. 721).
} 
Prova disso é que, nos países em que a consolidação do regime democrático e do estado democrático deu-se de forma diferenciada, verifica-se o desenvolvimento humano com maiores potencialidades. Veja-se, por exemplo, o que se extrai a partir do estudo de O’Donnell (2004, p. 47), que, ao propor uma classificação dos regimes contemporâneos na América Latina, afirma que Costa Rica, Uruguai e Chile são países nos quais o regime e o estado característicos da democracia estão basicamente satisfeitos; de outro norte, situa Brasil, México, Peru, Colômbia e Bolívia, dentre outros, como democracias políticas ou regimes políticos democráticos.

Nesse último grupo, segundo O’Donnell (2004, p. 47-48), “[...] há descontinuidades significativas em termos de alcance da legalidade do estado em várias regiões, incluindo características não democráticas de alguns regimes subnacionais", embora, segundo o autor, as características pertinentes sejam satisfeitas a nível nacional.

É o que se percebe ao analisar esses grupos de países quanto ao índice de desenvolvimento humano (IDH), por exemplo. Tomando-se por base o Ranking IDH Global 2014 divulgado pelo Programa das Nações Unidas para o Desenvolvimento (PNUD) no Relatório de Desenvolvimento Humano 2015, percebe-se IDH mais alto nos países do primeiro grupo referido por O'Donnell, comparativamente aos do segundo grupo. Conforme tais dados, Chile, Uruguai e Costa Rica situam-se nas posições 42, 52 e 69, respectivamente, enquanto México, Brasil, Peru, Colômbia e Bolívia ocupam as posições 74, 75, 84, 97 e 119, respectivamente (PNUD, 2014).

Já o relatório divulgado pelo PNUD em 2018, revelando o IDH referente aos anos imediatamente anteriores à publicação, têm-se índices bastante semelhantes, colocando os países acima referidos nas seguintes posições para os anos de 2016 e 2017, respectivamente: Chile, 44 e 44; Uruguai, 56 e 55; Costa Rica, 63 e 63; México, 74 e 74; Brasil, 79 e 79; Peru, 86 e 89; Colômbia 89 e 90; e Bolívia, 116 e 118 (UNDP, 2018, p. 22-24).

Analisando-se, especificamente, os índices relacionados à educação, o relatório divulgado pelo PNDU em 2018 coloca os países do primeiro grupo em patamar superior àqueles do segundo grupo (UNDP, 2018, p. 22-24). Segundo dados de 2017, Chile e Uruguai, por exemplo, possuem 16,4 e 15,9 anos, respectivamente, de expectativa de permanência na escola, enquanto Brasil e Colômbia possuem 15,4 e 14,4 anos, respectivamente, no mesmo critério. Já no que tange à média de anos efetivamente estudados, Chile e Uruguai apresentam 
índice de 10,3 e 8,7, respectivamente, enquanto no Brasil e na Colômbia os índices são de 7,8 e 8,3 , respectivamente.

Considerando-se que o IDH afere três dimensões básicas do desenvolvimento humano, quais sejam, renda, educação e saúde, percebe-se por meio dos dados transcritos que a democracia consolidada em determinado território relaciona-se, sobremaneira, com o desenvolvimento do povo nos setores primordiais apontados. Especificamente quanto à prestação educacional, resta determinante para o exercício da cidadania e da participação democrática nos países de maior desenvolvimento.

Claro que contextos específicos e problemas peculiares exigem respostas diferenciadas. Porém, segundo os estudos produzidos, verifica-se que a educação sempre será fomentadora da cidadania, por se constituir em alicerce da autonomia, da formação empoderadora e, por consequência, de conscientes processos de desenvolvimento democrático.

Isso se verifica independentemente de critério geográfico e temporal, uma vez que, entrelaçando-se o exercício dos direitos civis e políticos com a prestação adequada de direitos sociais não há que se falar em nação pobre virtualmente e/ou com democracia ineficiente, ante a consagração da legitimidade do poder estatal.

Dessa forma, não há como se desvincular o estudo da democracia com as ideias de cidadania e, por consequência, da linguagem de direitos, considerando-se que a inefetividade dos direitos instituídos é imprescindível, sob vários aspectos, para verificar a consolidação da democracia em determinados contextos. Tal afirmação se concretiza, especialmente, no que tange aos aspectos abordados do direito à educação enquanto sedimentador da autonomia em patamar hábil a propiciar o exercício da democracia pelos cidadãos.

\section{CONCLUSÃO}

A presente pesquisa constatou que exercer a democracia pressupõe participar da vida política além das eleições e do exercício do direito ao voto. Vivenciando mais cotidianamente da formulação, implementação e avaliação das políticas públicas e do controle dos atos do governo, ao fazê-lo em defesa de interesses que não são exclusivamente seus, percebeu-se que os cidadãos alcançam uma cidadania mais plena. Tal constatação explicitou-se ainda mais quando se vinculou a democracia com a prestação dos direitos sociais e, prioritariamente, do direito à educação, que é prestacional por natureza. Viu-se, portanto, que o nível de 
efetividade na prestação educacional é determinante para o fortalecimento da cidadania e o bom desenvolvimento dos processos democráticos.

Pode-se aferir, além disso, que a real democracia pressupõe aprender e exercitar uma cultura política tolerante à diversidade e a diferença. As implicações disso para - e com - a educação em todos os níveis revelou-se significativa, até porque um dos maiores desafios das políticas democráticas é como ensinar e aplicar suas condições culturais. Por conseguinte, quanto mais se verificou solidificada a educação, maior se vislumbrou a possibilidade de edificação de uma real democracia. Dessa forma, ainda que se esteja falando de modelos incompletos ou não consolidados, a democracia encontrou-se vinculada ao exercício da cidadania, gerada pela educação de qualidade.

Guillermo O’Donnell, classificando os regimes contemporâneos na América Latina, afirmou que Costa Rica, Uruguai e Chile são países nos quais o regime e o estado característicos da democracia estão essencialmente satisfeitos; por outro lado, situa Brasil, México, Peru, Colômbia e Bolívia, dentre outros, como democracias políticas ou regimes políticos democráticos com descontinuidade e não uniformização da consolidação democrática.

Analisando especificamente o contexto desses países quanto ao índice de desenvolvimento humano e a prestação educacional, segundo os dados apresentados neste estudo, percebeu-se que os países do primeiro grupo são mais desenvolvidos e apresentam maior efetividade na educação, evidenciando - para além das considerações teóricas - o elo entre a consolidação democrática e a educação. Mais: ao se averiguar, especificamente, a prestação educacional quanto à expectativa de anos de estudo e a média efetivamente cumprida de escolarização nos países apontados, tal constatação se confirmou quanto à vinculação determinante entre os elementos pesquisados (democracia, cidadania e educação).

Aferindo-se dados do índice de desenvolvimento humano (IDH) e de efetividade educacional divulgados pelo Programa das Nações Unidas para o Desenvolvimento (PNUD) referentes aos países classificados nos estudos sobre democracia por O’Donnell como aqueles nos quais o regime e o estado característicos da democracia estão basicamente satisfeitos, comparando-os com outros países da América Latina sem a mesma consolidação democrática, ratificou-se a premissa de que a educação, gestada no contexto da participação democrática, pode e deve ser vista como um dos grandes trunfos para concessão de empoderamento aos cidadãos. 
Assim, no contexto dos direitos sociais a serem prestados pelo Estado, corroborouse, com os dados obtidos, a sólida relação da efetividade educacional com a consolidação da democracia na América Latina, restando explícito o acoplamento entre a democracia, a cidadania e a educação, esta enquanto fornecedora de autonomia, de conhecimento e do poder de autodeterminação em todos os níveis e processos de escolha.

\section{REFERÊNCIAS}

ALEXY, Robert. Teoria dos direitos fundamentais. Trad. Virgílio Afonso da Silva. $2^{\mathrm{a}}$ ed., $4^{\mathrm{a}}$ tir. São Paulo: Malheiros, 2015.

BAEZ, Narciso Leandro Xavier; MOZETIC, Vinicius Almada. A morfologia das teorias universalistas dos Direitos Humanos Fundamentais. In: ALEXY, Robert; BAEZ, Narciso Leandro Xavier; SANDKÜHLER, Hans Jörg; HAHN, Paulo (org.). Níveis de efetivação dos direitos fundamentais e sociais: um diálogo Brasil e Alemanha. Joaçaba: Ed. Unoesc, 2013.

BLACK, Derek W. The Fundamental Right to Education. In: Notre Dame Law Review, v. 94, n. 3, 2019, p. 1059-1114. Disponível em: https://heinonline.org. Acesso em: 04 fev.2020.

COTLER, Julio. La nacionalización y democratización del estado, la política y la sociedade. In: O’DONNELL, Guillermo et al. La democracia en América Latina. Hacia una democracia de ciudadanas y ciudadanos, 2004.

ESPING-ANDERSEN, G. As três economias políticas do Wesfare State. Lua Nova, n. 24, 1991, pp. 85-116.

FERRAJOLI, Luigi. La democrazia costituzionale. In: Revus [Online], 18, 2012, p. 69-124. Disponível em: http://journals.openedition.org/revus/2291. Acesso em: 04 fev.2020.

FREIRE, Paulo. Educação como Prática da Liberdade. 19. ed. Rio de Janeiro: Paz e Terra, 1989.

GADOTTI, Moacir. Educação de adultos como direito humano. São Paulo: Instituto Paulo Freire, 2009.

GARCIA, Emerson. O Direito à Educação e suas Perspectivas de Efetividade. In:

Revista Jurídica Virtual. Vol. 5, n. 57. Fev.2004. Disponível em:

http://www.planalto.gov.br/ccivil_03/revista/Rev_57/Artigos/Art_Emerson.htm.

Acesso em: 03.mar.2021.

HELD, David Held. Estado de la democracia en America Latina. In: O’DONNELL, Guillermo et al. La democracia en América Latina. Hacia una democracia de ciudadanas y ciudadanos, 2004. 
KEOHANE, Robert O. Nominal democracy? Prospects for democratic global governance. International Journal of Constitutional Law, n. 13, 2015, p. 343-353. Disponível em: https://doi.org/10.1093/icon/mov029. Acesso em: 10 fev.2020.

MALISKA, Marcos Augusto. O Direito à Educação e a Constituição. Porto Alegre: Sergio Antonio Fabris Editor, 2001.

MARSHALL, Thomas Humphrey; CASADO, Ma. Teresa; MIRANDA, Francisco Javier Noya. Ciudania y clase social. Reis, n. 79, 1997, p. 297-344.

MÉNDEZ, Juan E. Sociedad civil y calidad da democracia. In: O’DONNELL, Guillermo et al. La democracia en América Latina. Hacia una democracia de ciudadanas y ciudadanos, 2004.

O’DONNELL, Guillermo. Notas sobre la democracia en América Latina. La democracia en América Latina. Hacia una democracia de ciudadanas y ciudadanos, p. 87-193, 2004.

ONU - ORGANIZAÇÃO DAS NAÇÕES UNIDAS. Declaração Universal dos Direitos Humanos. 1948. Disponível em <http://www.onubrasil.org.br/documentos_direitoshumanos.php>. Acesso em: 25 jan.2021.

PNUD - PROGRAMA DAS NAÇÕES UNIDAS PARA O DESENVOLVIMENTO. Relatório de Desenvolvimento Humano. 2014. Disponível em: https://www.br.undp.org/content/brazil/pt/home/idh0/rankings/idh-global.html. Acesso em: 21 abr.2020.

ROSANVALLON, Pierre. Dimensión social y nacional de la democracia. In: O'DONNELL, Guillermo et al. La democracia en América Latina. Hacia una democracia de ciudadanas y ciudadanos, 2004.

SANTOS, Boaventura de Sousa. Orçamento Participativo em Porto Alegre: para uma democracia redistributiva. In: Santos, Boaventura de Sousa (org.). Democratizar a Democracia. Os caminhos da democracia participativa. Rio de Janeiro: Civilização Brasileira, 2002.

SANTOS, Boaventura de Sousa; AVRITZER, Leonardo. Para ampliar o cânone democrático. In: Santos, Boaventura de Sousa (org.). Democratizar a Democracia. Os caminhos da democracia participativa. Rio de Janeiro: Civilização Brasileira, 2002.

SARLET, Ingo Wolfgang. A eficácia dos direitos fundamentais: uma teoria geral dos direitos fundamentais na perspectiva constitucional. Porto Alegre: Livraria do Advogado, 2012.

UNDP - United Nations Development Programme. Human Development Indices and Indicators: 2018 Statistical Update. 2018. Disponível em: http://www.hdr.undp.org/en/content/human-development-indices-indicators-2018-statisticalupdate. Acesso em: 21 abr.2020. 
WACHSMANN, Patrick. Libertés publiques. 7ème ed. Paris: Daloz, 2013 